\title{
LA AMISTAD COMO UNA EXPERIENCIA DE ENCUENTRO CON LOS OTROS
}

\author{
César Augusto Delgado Lombana * \\ doi:10.11144/Javeriana.uph33-66.aeeo
}

\begin{abstract}
RESUMEN
En este artículo se pretende tematizar la experiencia del aislamiento que, para Gadamer, caracteriza la forma como se establece un modo de habitar el mundo de la vida determinado por la tecnificación. Sostenemos que la amistad permite enfrentar el aislamiento que afecta a nuestra situación histórica. Para desarrollar este argumento el artículo se divide en dos partes: en la primera, se realiza una descripción de los ámbitos en los que se manifiesta el padecimiento del aislamiento y la autoenajenación; en la segunda, se explicita que la experiencia de la amistad nos permite hacer frente al padecimiento del aislamiento, es decir, se analiza cómo la amistad es un horizonte que lleva a recuperar la condición ontológica de comprendernos vinculados, condición que cada vez más se desdibuja del mundo tecnificado.
\end{abstract}

Palabras clave: aislamiento; soledad; amistad; amor a sí mismo; común

* Pontificia Universidad Javeriana, Bogotá, Colombia.

Correo electrónico: cesar-delgado@javeriana.edu.co, hermeneia18@gmail.com

Para citar este artículo: Delgado Lombana, C.A. (2016). La amistad como una experiencia de encuentro con los otros. Universitas Philosophica, 33(66), pp. 171-192. ISSN 0120-5323, ISSN en línea: 2346-2426, doi:10.11144/Javeriana.uph33-66.aeeo 


\title{
FRIENDSHIP AS AN EXPERIENCE OF ENCOUNTER WITH OTHERS
}

\author{
César Augusto Delgado lombana
}

\begin{abstract}
This article aims to thematize the experience of isolation that, for Gadamer, characterizes the way of inhabiting the lifeworld which is determined by technification. We maintain that friendship can face isolation affecting our historical situation. To develop this argument the article is divided into two parts: In the first one, we describe the areas where the condition of isolation and self-alienation is made manifest. In the second, we make clear that the experience of friendship allows us to cope with the condition of the isolation, that is, we discuss how friendship is a horizon leading to recover the ontological condition of our linked self-comprehension, a condition that increasingly blurs with the technological world.

Keywords: isolation; loneliness; friendship: love of self; common
\end{abstract}


El abandono de los amigos es abandono de la proximidad fundamental del otro.

(Gadamer, 1993, p. 110)

Solo en la conversación (y en la risa común, que es un consenso desbordante sin palabras) pueden encontrarse los amigos y crear ese género de comunidad en la que cada cual es él mismo para el otro porque ambos encuentran al otro y se encuentran a si mismos en el otro.

(Gadamer, 2002a, p. 207)

EN ESTE ARTÍ́CULO SE DESARROLLAN dos asuntos fundamentales que se encuentran relacionados: el primero es la experiencia del aislamiento y la autoenajenación que, para Gadamer, caracteriza el habitar del mundo de la vida determinado por la tecnificación; el segundo es la amistad, asumida por nosotros como una experiencia que posibilita enfrentar el aislamiento. En este sentido, el filósofo de Marburgo señala, en el ensayo titulado "El aislamiento como síntoma de autoenajenación” (1966), que precisamente nuestro momento histórico está afectado por la "enfermedad" de la autoenajenación, que es definida como la imposibilidad de acercarse a los otros porque el mundo de la proximidad, del encuentro, deviene extraño para los hombres. Así, puede decirse que "la autoenajenación es una expresión propia de una enfermedad de la sociedad, quizás también una expresión para el sufrimiento en la soledad" (Gadamer, 1993, p. 112). Esta enfermedad se manifiesta en un síntoma: el aislamiento, entendido como una ruptura de proximidad, que ocasiona el padecimiento de la soledad.

Para nosotros, el asilamiento se muestra en una primera experiencia de padecimiento de la soledad: en la experiencia de la separación con los otros. La fractura de los lazos de proximidad es ocasionada porque las prácticas cotidianas en las que se dan los encuentros de identificación y solidaridad son desplazadas, por ejemplo, por prácticas tendientes a la autosuficiencia, que potencian tan solo la competencia laboral y económica. La autosuficiencia encubre que nuestra trama del vivir juntos no está atravesada únicamente por la racionalización de las formas de producción, sino por una nota esencial según cual "nuestro ser es fundamentalmente un ser en relación con otro" (Gadamer, 2010, p. 27). El aislamiento 
ocasiona también un segundo padecimiento de la soledad: consiste en que no logramos vincularnos con nosotros mismos, es decir, en estos tiempos de la autosuficiencia, de la aceleración tecnológica que nos ensordece y nos impide escucharnos, es más difícil ser en la soledad, que nos dona la intimidad necesaria para pensarnos y capturar lo ausente. Cabe advertir, entonces, que una cosa es padecer la soledad y otra buscar la soledad (Gadamer, 1993, pp. 110-111).

Así las cosas, sostenemos que, para luchar contra la enfermedad y el síntoma que padecemos en la actual situación histórica, es preciso volver a la experiencia vital de la amistad, que abre el camino para la recuperación de la vinculatividad del hombre consigo mismo y con el otro (Gadamer, 2002b, p. 77). Esta experiencia de la amistad, según nos lo recuerda la lectura gadameriana de Aristóteles, tiene en la philautía - que ha sido traducida como "amor a sí mismo"- la fuente que lleva a pensar cómo, a través de estar vinculados con nosotros mismos, es posible aproximarnos a los otros (Gadamer, 1999, p. 135). La experiencia de la amistad sostenida por el suelo de la philautía nos invita a comprendernos vinculados por una condición, si se quiere ontológica, que cada vez más se desdibuja del horizonte del mundo tecnificado. Gadamer se refiere a la desaparición de la autorrealización junto a los otros. En efecto, si algo aprendemos gracias a la amistad es a concebirnos como seres finitos que despliegan su existencia al entender que "el otro, el amigo, significa mucho para la persona no en razón de la necesidad o la carencia, sino por el bien de su propia autorrealización” (Gadamer, 1999, p. 138).

Para dar desarrollo a lo propuesto, el artículo se divide en dos secciones: en la primera se realiza una muy breve descripción de cómo el aislamiento y la autoenajenación pueden ser captadas en tres experiencias concretas de nuestro mundo de la vida: a) la configuración del trabajo tecnificado en el cual el rol se hiperboliza, b) la liberación del consumo como forma de satisfacer el deseo desmedido, y c) la crisis de la juventud expresada en la desconfianza con respecto a los otros. Finalmente, en la segunda sección se explora cómo en la experiencia de la amistad aflora el sentido de la proximidad, retomando el ámbito que se le abre a Gadamer, al abrazar, a través de Aristóteles, la noción de philautía. 
1. El aislamiento como padecimiento de la soledad: sobre nuestra situación histórica

CON EL PROpósito DE REALIZAR la tematización de la experiencia del aislamiento, partamos de la descripción que Gadamer hace acerca de la misma y que, además, nos ayuda a no confundirla con la de la búsqueda de la soledad. Anota el filósofo de Marburgo (1993): "El aislamiento es una experiencia de pérdida y de soledad, el aislamiento se padece. [...] El concepto de autoenajenación es una expresión propia de una enfermedad de la sociedad, o quizá también una expresión para el sufrimiento en la soledad" (p. 112). Detengámonos en la afirmación anterior. El aislamiento es una experiencia de pérdida y soledad que genera padecimiento en aquel que experiencia la ruptura radical con algo o con alguien. Esta forma de interpretar el aislamiento nos conduce a preguntarnos: ¿por qué la autoenajenación y el aislamiento no deberían ser confundidas con experiencias tales como la búsqueda de la soledad?

En primer lugar, establezcamos qué caracteriza a la autoenajenación. Para Gadamer, la enfermedad de la autoenajenación es vivenciada como una pérdida de los lazos de confianza que nos vinculan al otro y al mundo de la vida. Esta pérdida degenera en un extrañamiento creciente con respecto a lo que aparecía como un horizonte de proximidad que permitía la identificación en un suelo común. De esta forma, la autoenajenación debería ser diferenciada, por ejemplo, de la situación que ocurre cuando dos personas se alejan; si bien es cierto que ahí se cifra una forma de extrañamiento frente a lo otro, esto no es todavía signo de una ruptura radical, en tanto se mantiene cierta "confianza" en una manera de restablecer la vinculatividad fracturada. En palabras de Gadamer (1993), “esto no es todavía separación, todavía no es ruptura, sino una creciente inquietud sobre un devenir falso de la proximidad confiada. La confianza no ha desaparecido todavía, pero hay algo así como una confianza que se desvanece" (p. 113). En contraste con lo anterior, la autoenajenación es la ruptura padecida, la imposibilidad de reconstituir horizontes en los que nos encontremos en la apertura para habitar auténticamente el mundo. Dicho en otras palabras, la autoenajenación nos impide a los hombres que en las prácticas cotidianas acontezcan los sentidos que llevaban a reunirnos con los otros. El mundo deviene extraño porque somos extraños para nosotros mismos y para los otros. 
Ahora ocupémonos de la experiencia del aislamiento. Dice Gadamer (1993) que "el aislamiento es una forma de la pérdida. Es la aproximación a otra cosa que en ello se pierde. En la experiencia del aislamiento parece haber también un sufrimiento de la soledad" (p. 110). En el aislamiento se padece la soledad como síntoma de pérdida y de abandono. Lo que se pierde es el otro y, con él, el mundo del encuentro; ese mundo del encuentro es la vida cotidiana, en la que los sentidos, los rituales, los símbolos nos mantienen juntos.

El mundo de la proximidad se le hace cada vez más extraño. Sabemos hasta qué punto es propio de la tendencia del aislamiento el que uno no pueda salir de ello y aproximarse a los demás, sino que es embebido por ello. Por eso el aislamiento tiene que ver con el devenir extraño del hombre en el mundo y en el mundo humano. (Gadamer, 1993, p. 113)

Por ejemplo, podríamos pensar en experiencias como el saludo con el vecino que nos abre a los que están muy cercanos y, sin embargo, anónimos. Hoy en día los del lado son extraños que debemos mantener lejos: ¡no es una casualidad que ya no sea de nuestro interés saber quiénes son nuestros vecinos! También la experiencia de reunirnos a conversar en la mesa con los amigos o los familiares es una vivencia rica en sentido, la mesa es uno de los espacios en los que se hace presente la diferencia en la que reconocemos lo común ${ }^{1}$. Empero, sentarnos a comer juntos ha perdido valor en nuestras vidas. Finalmente, la experiencia del trabajo, en la que nos vinculamos por un fin en común: transformar el mundo y servir a los otros, es ahora reducida a la experiencia desoladora de la competencia, en la que el otro ya no es el compañero con el cual se intercambia la palabra, sino con quien se compite para ascender en la cadena de producción. Al parecer la

1 Hace poco Josep Maria Esquirol publicó el libro La resistencia intima. Ensayos de una filosofía de la proximidad (2015). Allí se explora con gran profundidad cómo las prácticas cotidianas, por ejemplo, el comer juntos, son experiencias que permiten resistir a la disgregación, porque reunirse en torno a los alimentos es un ritual de proximidad, de encuentro con el otro y con uno mismo, nuestra vida juntos se renueva en estas prácticas tan simples y a la vez tan llenas de sentido que permiten el diálogo. En nuestro tiempo, sentarse a la mesa junto a los otros para dialogar ya no es algo "cotidiano", los alimentos se consumen al ritmo que se acelera el tiempo, ya no queda mucho tiempo para el ritual del comer. Anota Esquirol (2015): "Renovamos la vida juntos y la fruición de los alimentos la sintetiza la dimensión más anímica: sentarse alrededor de la mesa y compartir palabra y gesto. La vida en común depende del comer juntos, y de ahí que todas las imágenes del aislamiento -que no de soledad- tengan algo perturbador. El pan, la sal, la fiesta, el duelo y la paz: de todo esto que se comparte depende la siempre difícil y precaria comunidad del nosotros" (p. 8). 
sentencia de Jaspers aún nos inquieta: el aislamiento y la autoenajenación son la expresión más acabada de la "era de la responsabilidad anónima”. Al respecto recuerda Gadamer (2002b):

Karl Jaspers, mi antecesor en la cátedra de Heidelberg, calificó ya en el año 1930 nuestra época de «era de la responsabilidad anónima». Una calificación clarividente donde las haya. Cada día es más verdad. Es tan terriblemente cierta que incluso existen hoy en día clínicas en las que el paciente no conserva su nombre, sino que se los sustituye por un número. $Y$ de hecho no se puede por menos de plantearse enteramente en serio la pregunta de cómo es posible salvaguardar y seguir desarrollando, bajo las formas de vida de la revolución industrial y de sus consecuencias, las cosas que realmente soportan la felicidad humana. (p. 77)

Para el filósofo de Marburgo, la enfermedad de la autoenajenación se muestra y se padece en el aislamiento, esta peculiar forma de vivenciar el padecimiento de la soledad en la que nos vemos agobiados por la carencia de identificación que impide la cercanía y el encuentro en la esfera de lo común.

Con esta forma de interpretar el aislamiento, ahora es el momento adecuado para detenernos -muy brevemente- en la descripción de lo que significa la búsqueda de la soledad. Para Gadamer, en esta experiencia lo buscado no es, como puede suponerse la soledad, sino "quedarse ahí junto a algo, tranquilo con respecto a todo" (Gadamer, 1993, p. 111). ¿Qué significado tiene esta experiencia para nosotros? La búsqueda de la soledad es la experiencia de demorarse en uno mismo, de habitar en los sentidos que nutren la existencia; entonces, lo buscado en la soledad es la posibilidad de estar junto a algo que se anhela, de capturarlo en el recuerdo. Por ejemplo, el filósofo busca la soledad para escuchar el pensar, para poder alcanzar el elemento, la senda por la que debe avanzar su meditar. También el hombre que ama busca la soledad, porque desea encontrar el medio más indicado para poder fijar su atención en aquello que desea, se desea capturar lo que está ausente (Gadamer, 1993, p. 111). El viejo, por su parte, busca la soledad para entregarse a sus recuerdos, es decir, trata de capturar la vida que se apaga, el camino: "piénsese en la época tardía de Rembrant; en la soledad de la mirada que ensombrecida nos contempla: ya no se ve nada más, porque ya no espera nada más, porque ya no mira hacia adelante, sino que mira en sí" (Gadamer, 1993, pp. 111-112). Indica el filósofo de Marburgo que la soledad del sabio tampoco es correctamente 
entendida si se asume como abandono. En efecto, la existencia del sabio es un testimonio de lo que significa la búsqueda de la soledad. Por ello, dice Gadamer (1993): "Zarathustra en la poesía de Nietzsche, continuamente busca la soledad. Lo que le hace tan solitario es saber, un saber que lo separa de los otros y que él busca a través de toda la historia de su vida solitaria: la mirada en el hundimiento de todos los valores precedentes" (p. 112). Finalmente, la búsqueda de la soledad es expresada en la experiencia cristiana, el creyente en la soledad tiende a la búsqueda del hijo de Dios. Por esta razón, puede decirse que "hay soledades incomparables en su compartir. En realidad, sólo quien es capaz de soledad puede estar de veras con los demás" (Esquirol, 2015, p. 9).

En suma, mientras el aislamiento es una experiencia de ruptura con lo otro que causa el sufrimiento de la soledad, en la búsqueda de la soledad lo que se anhela es estar más cerca de lo otro, se busca la proximidad con aquello que se escapa a la presencia. Para Gadamer (1993), "la soledad es, por tanto, algo completamente distinto al aislamiento. El aislamiento es una experiencia de pérdida [...] la experiencia de la renuncia. En la soledad se busca algo” (p. 112).

Es momento de dar un paso adelante. Según lo dejamos planteado, la autoenajenación puede ser tematizada de forma más precisa al atender a lo que sucede en tres esferas concretas de la vida cotidiana, a saber: en el trabajo tecnificado, en el consumo desmedido y en la crisis de la juventud, siendo esta última la que quizás más preocupa al filósofo. Con respecto al trabajo tecnificado, la autoenajenación se experiencia en la atomización de las funciones que debe cumplir el sujeto. Esta atomización se trasluce en la cada vez más creciente exigencia de "hacerse profesional". El "profesional" es entendido como parte de un mecanismo que conforma el engranaje de producción y circulación, en el cual solo se tiene una "relación" impersonal con lo otro. En este sentido, el otro es asumido como un rol, rol que puede ser intercambiado, renovado e incluso suprimido si ya no tiene funcionalidad. Los hombres y las mujeres nos comprendemos como meros eslabones autosuficientes en una imparable cadena de tecnificación: "llamamos profesión a la forma en que, en la sociedad actual, la ocupación se organiza en división del trabajo y determina la posición del individuo en ella" (Gadamer, 1993, p. 114).

El profesional no tiene la manera de identificarse con el trabajo en conjunto, está entregado a padecer el aislamiento radical al que es sometido por la forma en que son estructuradas las prácticas de ocupación laboral en nuestra sociedad; acá 
el aislamiento explicita con toda su fuerza la enfermedad que padecemos. En efecto, la autoenajenación en el trabajo impide que en él se nos abran formas de vinculación con lo general, con el conjunto entero de nuestras vidas y las vidas de los otros. Por ello, Gadamer (1993) afirma:

Deberíamos preguntarnos aún en qué se contribuye a la vida de la sociedad en conjunto, con este permanecer-en-una-profesión. Algo me parece cierto: el que la desaparición de la posibilidad de identificación con lo general es lo que llamamos autoenajenación del hombre [...]. El lamento por esta autoenajenación del hombre [...] en la que cada individuo sólo está ocupado como una ruedecilla o como un eslabón, sin que [...] para su propia conciencia esté vinculado a la ocupación del conjunto. (p. 114)

Al hiperbolizarse el rol del profesional, se exige que cada hombre y mujer que hace parte del eslabón de producción sea autosuficiente. En efecto, en estas circunstancias el otro no es vital para la comprensión de nosotros mismos, es necesario por mor de la "utilidad", es decir, de la "capacidad" para hacer aisladamente lo que se le ha asignado. Cada hombre que no sea competitivo al final será reemplazado, y la máxima que impera es, entonces, "la intercambiabilidad de cada uno". Esto tiene por resultado que el otro es asumido en términos de la "utilidad" o "inutilidad" dependiendo de si puede ser más "eficaz" y "eficiente”. Señala Gadamer (1993): “[1]o que experimentamos aquí es, [...] una esclavitud de todos nosotros, y ésta es para mí la autoenajenación de la que hay que hablar hoy en día" (p. 115). Insistamos en que no es posible que perdamos de vista que cada uno de nosotros es oprimido por este padecimiento de ser tratado como una pieza más reemplazable sin problema. A su vez, este mundo de la vida determinado por la autosuficiencia se revela agobiado por una nueva forma de presión: somos puestos en el límite de nuestras fuerzas, es decir, debemos producir a costa de nuestra vida y de la vida de los otros, pero, también, somos eliminados porque la tecnificación nos hace lucir cada vez menos capaces de poder competir frente a su mano poderosa e imparable².

2 Con respecto al desplazamiento del hombre por la tecnología, Zoja (2014) asegura: "[1] os otros hombres siempre le han sido necesarios, en todo sentido. Hoy, su función puede ser en gran parte reemplazada por máquinas (por ejemplo, la computadora). Pero aquello que no puede ser sustituido es la presencia humana: la lejanía de los otros causa una privación que es un verdadero daño psíquico. El hombre solo encuentra la depresión; y, en un círculo vicioso, el hombre deprimido es un hombre a quien le falta la fuerza y el impulso para ir al encuentro del prójimo" (p. 13). 
La segunda forma de autoenajenación es la generada por lo que Gadamer denomina como la presión del consumo. Es preciso indicar que ningún sujeto puede sustraerse a la fuerza masiva que en nuestra vida cotidiana tiene la altísima producción de objetos que deben ser consumidos inmediatamente por alguien: "la organización de compray consumo está exigida formalmente por la misma construcción de nuestro sistema económico" (Gadamer, 1993, p. 116). El sujeto inserto en las prácticas del mercado es un agente que a diario se ve expuesto a la urgencia de satisfacer nuevas necesidades sin las cuales, al parecer, la vida no podría realizarse. Ser hombre en los términos del mercado consiste en apropiarse y satisfacer estas necesidades "cuando la corriente de los deseos de consumo sincrónicamente generados le arrastran a uno por la puerta de los grandes almacenes" (Gadamer, 1993, p. 116). La presión del consumo autoenajena porque somos llevados a ocuparnos de forma extrema de nuestras necesidades individuales. Con esto se pierde de vista la posibilidad de preguntarse por la responsabilidad que tenemos frente a las demandas y las necesidades de los otros. Así, es posible afirmar que nos encontramos tan enfrascados en la satisfacción de los deseos particulares que es muy difícil que se constituyan lazos de vinculación que rompan con el aislamiento.

Agreguemos a lo anterior que la proyección del deseo, aunque recae en objetos, también opera a través de los hombres que son hechos objeto. En efecto, la presión por consumir y satisfacer el lujo y el derroche desmedido no solo tiene que ver con la adquisición de tecnología de punta, sino también con la construcción del sí mismo siguiendo modelos artificiales que se proyectan como algo por conquistar.

Con todo, es posible asegurar, siguiendo a Zoja (2014), que con la proyección del modelo humano de consumo se genera la obsesión entre los hombres y mujeres por conquistar algo que no somos, pero que deseamos ser, algo que no podremos nunca alcanzar, pero que en la obsesión de la que estamos presos nos empeñamos por abrazarlo como si eso fuera la conquista de otro casi sagrado. Nuestra obsesión nos lleva al desprecio de nosotros mismos y de los otros, en tanto no corresponden con el modelo artificial proyectado por el mercado. Esto tiene por resultado que nos condenemos al aislamiento, a la imposibilidad de aproximarnos, por ejemplo, en un sentido de finitud constitutiva que es reemplazada por un instinto de inmortalidad proyectada en los hombres modelos de consumo.

Así, los hombres y las mujeres arrinconados por la presión del consumo no pueden ver más que su sí mismo puesto en "otro" ajeno a él; el otro no es el otro 
de carne y hueso, sino el "otro" modelo de mercado. Esta presión condena a la locura narcisista de querer ser como "otro" que sacia a nuestro yo: yo deseo ser modelo de hombre, yo quiero ser como ese "otro" que es también un modelo que reproducir, yo soy todo y quiero ser como el "otro" para ser un mejor yo. Entonces, el pronombre "yo" se convierte en la fórmula favorita no solo de este sí mismo, sino del mercado que hace de ese yo un niño que deber ser hiperbolizado: "La vergüenza del narcisismo - que era común a gran parte de las culturas tradicionales- se ha desmoronado ante los embates del mercado, que vende lo superfluo y estimulan la autocomplacencia" (Zoja, 2014, p. 10).

Finalmente, llegamos a la tercera experiencia en la cual se hacen manifiestos el aislamiento y la autoenajenación: la crisis de la juventud. Es de notar que en la experiencia del aislamiento por parte de la juventud se puede sentir el eco de las anteriores dos experiencias en las que hace su aparición la pérdida de proximidad. Tanto para Gadamer, en el artículo titulado: "Humanismo y revolución industrial” (2002b, p. 39), como para Zoja, en el texto: La muerte del prójimo (2014, pp. 42-43) $)^{3}$ los jóvenes crecen determinados por una marca de agua que configura sus forma de comprenderse frente al otro, a saber: la desconfianza. La desconfianza de los jóvenes con respecto a lo otro se deja ver en tres esferas concretas: a) imposibilidad de confiar en la tradición; b) desconfianza frente a las relaciones de trabajo, y c) desconfianza frente a su otro concreto.

Detengámonos en la primera esfera, la desconfianza frente a la tradición. La juventud se siente poco identificada con el suelo nutricio de la tradición. Esta nada les dice, dado que los valores que aquella exalta y profesa no se muestran fiables, por lo que los jóvenes echan mano de lo ocurrido en las guerras y en los constantes brotes de violencia para asegurar que la tradición está en decaimiento: "nuestra juventud se siente pesimista recurriendo al expediente de buscar sus causas en las desgracias del siglo, en los fracasos de las generaciones anteriores"

3 Aunque, como puede verse, esta forma de caracterizar las experiencias en que el aislamiento deja oír su voz se ha realizado siguiendo a Gadamer, es importante anotar que tanto Gadamer (19661999) como Zoja, más recientemente (2014), coinciden en que quizás la pérdida de proximidad es experienciada con toda su violencia en un sujeto en particular, los jóvenes. Zoja (2014, p. 43) realiza unas descripciones de gran relevancia para hacer visible que los jóvenes crecen agobiados por el aislamiento, impuesto no solo por la tecnología, sino también por la imposibilidad que estos sienten de poder identificarse con la tradición. 
(Gadamer, 2002b, p. 41), lo cual tiene por consecuencia que las nuevas generaciones padezcan la soledad al no poder identificarse ni con sus otros más cercanos, por ejemplo, la familia, ni con símbolos dados por el Estado o cualquier otra institución. Fijémonos en lo que ocurre en el sistema escolar de nuestras sociedades.

Los jóvenes se sienten imposibilitados de acercarse a lo otro y en esa imposibilidad se refugian en la tecnología y en el mercado que les proyecta modelos artificiales, los valores presentados por estos alimentan el narcisismo y el desprecio por prácticas cotidianas en las que el sí mismo y el otro se aproximan; por ejemplo, tomar un café es reemplazado por largas horas navegando en Internet, que proféticamente aparece como un medio para aproximarnos a los otros. Sin embargo, lo que ocurre es algo distinto: "si basta un botón para acercarnos al otro, lo que en verdad pasa es que nos retira a una inalcanzable lejanía" (Gadamer, 2002b, p. 47). El rostro de carne y hueso es suplantado por el hombre sin rostro de la realidad creada por el medio virtual, pero también el rostro finito, marcado por las huellas de la vida, es eliminado por el mercado que, a través del mundo virtual, propaga el ideal de perfección del sujeto modelo, algo inalcanzable, pero que se muestra como el único valor por el cual debe darse la vida. En suma, la tradición ya no le dice nada a esta nueva generación, su voz se ha silenciado y en su lugar aparece la fuerza de la creciente tecnologización que ha degenerado en aislamiento. Al respecto, afirma Zoja (2014): "están ausentes de la vida, pero tal vez su renuncia sea, en el origen, una búsqueda de algo que está ausente en la sociedad” (p. 43).

Acerca a la desconfianza de los jóvenes frente al sistema laboral, lo que puede observarse es que la creciente burocratización y exigencias de tecnificación reclaman a las nuevas generaciones dar mayor rendimiento y aprender a ganar habilidades para lograr moverse con solvencia y afrontar los retos que el mercado laboral exige. En efecto, las exigencias realizadas son cada vez más altas, tan altas que parecen inalcanzables y cuando se supone son concretadas por alguien, inmediatamente el mercado laboral impone un nuevo reto, los jóvenes se quedan sin aliento ante la insoportable presión que sobre ellos recae.

$\mathrm{Al}$ individuo que trata de abrirse un camino se le niega una y otra vez esa confirmación directa que busca su propia autoconciencia aún no acreditada: el derecho a ser joven, a no saber todavía si las fuerzas estarán a la altura de lo que la vida le va a exigir a uno. [...] Nuestra juventud [...] tiene que 
acreditarse dentro de un sistema social y de producción cada vez más funcional y burocratizado. (Gadamer, 2002b, p. 41) ${ }^{4}$

No hay que olvidar, además, que el mercado laboral impulsa el valor del individualismo, de la desconfianza frente al otro que es una competencia y puede arrebatarnos el cargo por el que "todos posiblemente daríamos la vida”. Todo ello, anudado con lo expuesto anteriormente, permite afirmar que los jóvenes se encuentran aislados, padeciendo la soledad que les impone el mundo; el "otro" es "otro" que encarna el espíritu de lo que se debe alejar, el "otro" no es digno de confianza, el "otro" es un número que se debe desechar para escalar.

Finalmente, los jóvenes experiencian el aislamiento, el padecer la soledad ante la pérdida de proximidad cuando al alzar la mirada encuentra que el otro, el amigo ya no está: "el abandono de los amigos es abandono de la proximidad fundamental del otro" (Gadamer, 1993, p. 110). Esta es la experiencia humana concreta que a las nuevas generaciones se les hace más difícil de entender, en un mundo en el que Internet habla de conectarse con cientos de amigos en línea, amigos de los que escasamente se conoce el nombre y cuyo rostro es una fotografía de la que no tenemos certeza respecto a su realidad, su forma o su vida ${ }^{5}$. Amigos que disparan multitud de palabras en el muro virtual, lamentándose porque nadie los escucha; y gritan, reclaman proximidad, pero esa proximidad sigue siendo imposible porque prefieren la pantalla al rostro, amigos por todos los lugares del mundo,

4 Gadamer de logró demostrar que una manifestación de la enfermedad de nuestras sociedades es el fenómeno de la presión del rendimiento, el cual conduce al aislamiento: "Hará unos diez años que coincidí por primera vez en las calles de Colonia con un reportero que estaba hablando a la gente, y me acerqué a escuchar. Les preguntaba si no les agobiaba la «presión de rendimiento» bajo la que se encontraban. [...] Para mí tenía algo de abrumador que el rendimiento se considerase como algo ajeno" (Gadamer, 2002b, p. 48). Más recientemente, han ha pretendido mostrar, no muy lejos de Gadamer, cómo se instaura contemporáneamente en nuestras sociedades el fenómeno que caracteriza a nuestros sistemas laborales y de producción: "La sociedad del rendimiento se caracteriza por el verbo modal positivo poder sin límites. [...] Los proyectos, las iniciativas y la motivación reemplazan la prohibición, el mandato y la ley. [...] La sociedad de rendimiento [...] produce depresivos y fracasados" (Han, 2012, pp. 26-27).

5 En La sociedad de la transparencia se resalta que «el "rostro humano" con su valor cultural hace tiempo que ha desaparecido de la fotografía. La época de Facebook y Photoshop hace del "rostro humano" una faz que se disuelve por entero en su valor de exposición. La faz (face) es el rostro expuesto sin «aura de la mirada». Es la forma de la mercancía del «rostro humano». La faz como superficie es más transparente que aquel rostro o cara que, para Emmanuel Lévinas, constituye un lugar señalado en el que irrumpe la trascendencia del otro" (Han, 2013, p. 27). 
aunque al final nadie está. ¡Qué extraña forma de relacionarnos, en la que en la vida concreta, en la cotidianidad, el otro encarna aquello de lo que radicalmente debo alejarme, desconfiar, huir! Sin embargo, en la red aparece un aire de confianza tan turbio que no puede diferenciarse a nadie ni a nada; en la red se expresa el padecimiento de la soledad por el abandono en el que estamos.

\section{Amistad y philautía: hacia el encuentro con nosotros mismos y el otro}

ANTE LA ENFERMEDAD Y AL SÍNTOMA que afectan a nuestra situación histórica, Gadamer nos invita a entregarnos al diálogo con nosotros mismos y con el otro $^{6}$. En un primer momento, el otro es la tradición griega a la cual podemos preguntarle con el fin de descubrir la apertura a una posibilidad de comprendernos a nosotros mismos siguiendo la voz de un amigo-compañero de diálogo. Le preguntamos a la tradición no con el ánimo de encontrar en ella la ilusión de una tierra prometida a la que debemos regresar. Por el contrario, el filósofo de Marburgo sabe que ese otro quizás pueda aportarnos sentidos que nos permitan vislumbrar una especie de alivio a la enfermedad y al síntoma que nos aquejan. Podemos decir con Gadamer (2001b), en suma, que "a pesar de todo, considerar la oferta del pensamiento griego no me parece que equivalga a una vuelta romántica al pasado, sino un acordarse de lo existente" (p. 184).

De esta forma, al preguntarle en particular a Aristóteles por cómo él se entendió a sí mismo vinculado por un suelo común, una morada -oíkos- en la que los hombres experimentaban la cercanía, lo propio, pero a su vez lo diferente como una condición de la trama del vivir juntos (Gadamer, 1999, 137), nos recuerda que para el pueblo griego la vida era pensada fundamentalmente orientada por el sentido de acogernos en la condición ontológica que nos recuerda que "nuestro ser es fundamentalmente un ser en relación con otro” (Gadamer, 2010, p. 27), sentido que para nosotros es difuso a causa de la experiencia del aislamiento.

Al preguntarle a Aristóteles nos cuestionamos a nosotros mismos y nos exponemos a uno de los riesgos fundamentales de todo diálogo, de toda experiencia

6 Nuestra tarea es, entonces, comprender el esfuerzo de diálogo como «la labor hermenéutica [...] al evento comunicativo que no es la "repetición de algo pasado sino de compartir el significado en el presente” » (Risser, 1996, p. 394). 
auténtica de cercanía con el otro. Siguiendo a Caputo (2002), podemos llamar a este riesgo como el "riesgo de comprensión hermenéutica" (p. 513). Recordemos que para el autor de Verdad y método el diálogo con el otro tradición, el otro texto, el otro obra de arte y, fundamentalmente, el otro de carne y hueso supone que, al escuchar al compañero de conversación, nuestra época se expone al riesgo de ser co-modificada en su ser mismo. Pero debemos advertir que no hay posibilidad de escucha si no estamos dispuestos a arriesgarnos a permitir que la voz del otro nos oriente; para esto sería necesario poner en juego nuestros prejuicios, es decir, exponemos con el ánimo de dejar venir esa palabra que le susurra al oído de nuestra época ${ }^{7}$.

Debemos entregarnos a la experiencia de saber de nosotros mismos gracias al otro: "por eso el preguntar es más un padecer que un hacer, la pregunta se impone; llega un momento en que ya no se la puede seguir eludiendo ni permanecer en la opinión acostumbrada" (Gadamer, 2001a, p. 444). A la experiencia de diálogo, que ahora desearíamos comenzar, le es necesario como condición un oído que Caputo denomina, siguiendo a Gadamer, un "oído circuncidado" (Caputo, 2002, p. 514). Este oído está abierto a la voz del otro y dispuesto a exponerse a eso otro, dispuesto a salir de sí mismo para que lo otro le indique un horizonte; podemos decir que nuestra época requiere de un "espíritu hermenéutico de la amistad" (Caputo, 2002, p. 514) que lo vincule consigo mismo y con el otro.

Acogiendo este horizonte, para Gadamer, la amistad descrita a fondo por Aristóteles nos permite pensar en torno a dos sentidos que nos ayudan a comprender qué nos puede decir a nosotros la experiencia griega de que "nuestro ser es fundamentalmente un ser en relación con otro". El primer sentido es el que acontece de la expresión philautía entendida como "amor a sí mismo". El segundo sentido, que nos hereda el meditar griego, es la idea de autorealización de nosotros mismos

7 Como hemos dicho en otro lugar, el esfuerzo de poner en juego los prejuicios es "una evaluación de las precomprensiones que se ponen en movimiento al instante de vincularse con la alteridad. Por supuesto, este ponerse en juego no es la "verificación" de un juicio, la absolutización de la verdad de la que se cree estar en posesión. La apertura implica que se reconoce la finitud de la visión que se tiene sobre el otro. [...] Si todo prejuicio es finito y rompe la aspiración de unidad, entonces es en el estar vinculados con el otro, orientado-al-otro que esta fractura se nos puede dar como la posibilidad de la comprensión" (Delgado, 2011, p 205) y, ver también (Delgado, 2012, pp. 25-30). 
en tanto finitos y vinculados al otro. Finalmente, estos dos sentidos son recogidos por el Estagirita en la palabra philia-amistad, que Gadamer interpreta como el horizonte de lo común entre el sí mismo y el otro (Gadamer, 2002b, p. 80).

Detengámonos, por un momento, en una breve comprensión de la expresión philautía. Esta expresión le permite a Gadamer pensar dos asuntos: el primero es cómo, por ejemplo, para Aristóteles en la Ética a Nicómaco (1168b) la idea de constituir las relaciones entre los hombres está atravesada por el presupuesto de que nadie puede ser amigo si no es capaz de ser primero amigo de sí mismo, sino que el alma del amigo debe estar en armonía para poder acoger a los otros. Esta idea obliga a Gadamer a preguntarse: ¿cómo la philautía puede ser una condición de la amistad? Para responder esta cuestión, el autor de Verdady método recuerda que el amor a sí mismo no debe ser entendido siguiendo el patrón común, es decir, como sinónimo de egoísmo.

Hay en griego una palabra que ahora podrá parecer chocante, y que se lo parecía sin duda a los griegos, aunque no formulasen mayores interrogantes al respecto: la philautía, «el amor a sí mismo». Pues bien, de eso se trata, de hallar en el amor a sí mismo el verdadero fundamento y condición de cualquier tipo de vinculación con otros y vinculatividad para uno mismo. (Gadamer, 2002b, p. 82)

Así, para Aristóteles en la Ética Nicómaco, philautía no mienta la experiencia del hombre que solo piensa en sí mismo y se lanza a la satisfacción de sus deseos, queriendo con ello dejar de lado a los otros y a los bienes que en realidad son apreciados por aquel que está orientado por el bien. Philautía muestra el sentido, la experiencia del hombre que, amando el bien, queriendo para sí lo mejor, es capaz de amar al otro en sus fines. El hombre egoísta no puede amarse a sí mismo porque se encuentra agobiado por sus deseos y es tiranizado por ellos; el egoísta no está en armonía porque le presta atención solo a la parte concupiscible de su alma, dejando de lado a la razón que anhela la mayor de las riquezas. Por el contrario, insistamos, el hombre virtuoso en su acción abraza el bien y eso le permite abrazar a los otros, quererlos en sus fines en tanto él ama los suyos, él ama lo mejor de sí y del otro: "el hombre bueno debe ser amante de sí mismo (porque se ayudará a sí mismo haciendo lo que es noble y será útil a los demás), pero el malo no debe serlo, porque, siguiendo sus malas pasiones, se perjudicará tanto a sí mismo como al prójimo" (Et. Nic., 1169a). 
$\mathrm{Al}$ aclarar el sentido de la expresión philautía, Gadamer considera que, frente al padecimiento de la soledad causado por el aislamiento, la experiencia griega de la amistad nos invita a recordar que nosotros debemos ser para cada uno nuestra morada, en la cual el otro tiene cabida, se le deja venir porque en el otro se abre la posibilidad de saber de nosotros mismos, de lo sorprendente, de lo inesperado, aprehendemos de aquello que nos vincula, fines compartidos que todos deseamos abrazar en nuestra experiencia cotidiana. Ser amigos de nosotros mismos supone que me reconozco en mi diferencia, en mis posibilidades y límites y, a su vez, que soy capaz de ver en el otro una morada -oíkos-, una posibilidad, en que la diferencia nos permite pensar lo común: "este término [oikos] sigue llevando consigo, como una connotación familiar a todos, aquello que constituye el sentirse en «casa» donde todo le es familiar a uno" (Gadamer, 2002b, p. 80). A lo anterior vale la pena agregar que Gadamer llama a esto "casa" u "hogar", recurriendo al término griego oikeion. Aunque nosotros generalmente asociamos este término a la economía, Gadamer señala que esto también puede connotar la "amistad". Él trata al oikeion como un aspecto misterioso de la amistad, una conexión "sobre la cual nosotros no podemos hablar" porque es "algo escondido" y así difícil de tenerlo a la vista (Walhof, 2006, p.577).

Recordemos que en la descripción sobre las tres experiencias del aislamiento en las que se muestra la enfermedad de la autoenajenación, lo que se puede vivenciar es que nos vemos abocados a no poder reconstituir lazos de vinculación con el otro ni con nosotros mismos: en el trabajo tecnificado prima la profesionalización, que nos impide un encuentro con lo general; en la presión del mercado agobia una forma de encerramiento sobre la necesidad particular; en la crisis de los jóvenes estos son acosados por la desconfianza frente a un mundo cada vez más burocratizado, que va en detrimento de prácticas concretas de vinculación.

Es por esta razón que Gadamer regresa al sentido de la philautía para recordar a modo de orientación que es necesario pensar que la vinculación con nuestro mundo compartido requiere del "amor a sí mismo", el cual nos permite ver en el otro lo común, lo cercano y, a su vez, en lo diferente lo común ${ }^{8}$, sentidos que

8 En el artículo titulado "Entre el extrañamiento y lo común. En torno a la noción de amistad desde la hermenéutica de Gadamer" (2013) se explora lo que es posible denominarse los modos de relación que caracterizan a la amistad, a saber: lo común y el extrañamiento. En efecto, en el artículo 
no deberían ser olvidados en aras de conquistar prácticas en donde prima la individualidad extrema y el deseo de superioridad frente a lo otro en formas de autosuficiencia. En suma, la philautía nos hace entender que somos responsables de nosotros mismos y del otro, que vivencias concretas como el trabajo, las relaciones amorosas, las vinculaciones entre colegas, entre otras, presuponen la amistad con uno mismo, esta forma de acogerse y ser acogido por el otro:

[Philautia] quiere decir que uno tiene que poder ponerse siempre de acuerdo consigo mismo. Que uno tiene que estar primero de acuerdo consigo mismo, si quiere ser también un amigo para el otro, o un simple amante, o un simple amigo de negocios o colega profesional. El que no es capaz de estar de acuerdo consigo mismo será sentido siempre como un obstáculo y como algo ajeno a la convivencia entre la gente. (Gadamer, 2002b, pp. 82-83)

Con todo, es necesario preguntar ahora: ¿qué es lo que reconozco en la experiencia de la amistad? Este es el segundo sentido que debe ser comprendido. Para el autor de Verdad y método, Aristóteles ve que en la experiencia de la amistad se hace posible asir en el logos el imperativo del Oráculo de Delfos: "conócete a ti mismo”. No obstante: ¿qué nos dice a nosotros en nuestra situación histórica este imperativo? En contraste con la sociedad dominada por el deseo de autosuficiencia, que se opone a la autorealización de nuestro ser finito que ve en el otro una posibilidad de acogimiento de nosotros mismos en nuestros límites, "el conócete a ti mismo" nos hace un llamado a reconocernos como hombres de carne y hueso, con limitaciones y posibilidades, nos llama a saber de nosotros en nuestra fragilidad:

mencionado se indica que los textos tardíos del filósofo de Marburgo se concentran en explorar cómo la amistad es un suelo de lo común. Gadamer observa que nuestras sociedades carecen de formas de vinculación que permitan una experiencia de vida en comunidad, resquebrajada porque no se hace de lo compartido el suelo de las diferencias. No obstante, se indica en el artículo que aunque Gadamer insiste en la importancia del horizonte de lo común, ello no significa que el filósofo no deje las pistas para pensar cómo es que en lo común tiene su morada la diferencia y el extrañamiento, modos de relación que permiten que nos acojamos constituidos en nuestro ser por el otro: "La experiencia de la amistad debe contemplar este horizonte que deja ver la radicalidad del otro: así como se puede estar dispuesto a dejar valer la alteridad en sus pretensiones, aparece a su vez la tensión de un punto de vista contrario que puede entrar a negar la posibilidad del acuerdo. [...] La experiencia de la amistad en lo común implica que este suelo está constantemente en fractura, para dar paso a otro modo de ser con la alteridad" (Delgado, 2013, p. 10). 
De cualquier manera, esto pertenece a la consciencia más profunda de un ser humano que él necesita para saber sobre sí mismo, que él no es un dios. Recordemos esto fue el punto del imperativo del oráculo de Delfos. Cuando Aristóteles apela a esto aquí, él se propone esto, simplemente, en el sentido práctico de alguien que sigue esta admonición estará abierto a las relaciones con otros. (Gadamer, 1999, p. 137) 9

Gadamer recuerda cómo Aristóteles evidenciaba que, en comparación de los dioses que, en tanto perfectos, no necesitan de amigos, el hombre determinado por su ser finito necesita del otro, no a la manera de complemento; por el contrario, es con el otro en tanto que es carente y se coge en su carencia y es capaz de amar la carencia del otro que la vida puede ser abrazada en su riqueza y posibilidad, es decir, la autorealización es junto a los otros ${ }^{10}$. De esta forma, reconocer que nuestra finitud nos abre a la diferencia y a lo común es el sentido de la amistad que no podemos olvidar, este es el segundo sentido que la tradición griega nos hereda para que enfrentemos el aislamiento. En palabras de Gadamer (2002b): "Conoce que eres solo un hombre, no el producto de una providencia divina, ni el ungido por algún carisma especial, ni nadie a quien se le garanticen, más acá y más allá de todas las vinculaciones humanas, privilegios, victoria, y éxito. Nada de eso" (p. 84).

De esta manera, en la amistad se reconocen nuestros límites y posibilidades, nos reconocemos carentes y frágiles, reconocemos que el otro es una posibilidad que se nos abre cuando estamos vinculados con nosotros mismos. La amistad es, por ello, una experiencia que recoge quizás lo más querido por la herencia aristotélica: que la trama de la vida compartida se constituye en las tensiones dadas entre lo común y lo diferente, que al aprehender esta indicación es posible que se dé la

9 Carlos B. Gutiérrez (2010) siguiendo a Gadamer, afirma: "Aristóteles invoca también el argumento, antimoderno podríamos decir, de que lo esencial del amigo consiste en que uno más fácilmente puede conocer a otro que conocerse a sí mismo. Sabemos bien cuán fácilmente nos engañamos sobre nosotros mismos y cuán inacabable resulta la tarea de auto-conocernos. La lectura que hizo Gadamer de este paso despliega muy bien la riqueza de la participación. Conocerse a sí mismo en el espejo que es el amigo apunta a lo común entre el uno y el otro hacia lo bueno" (p. 263).

10 En este sentido, podemos indicar que, "Gadamer asocia la amistad con el incremento de nuestras habilidades prácticas, considera que necesitamos amigos, precisamente, por nuestra finitud. Elucida este punto a partir precisamente de la distinción que encuentra en la discusión sobre la amistad en Aristóteles, entre la autosuficiencia (autarkeia) y el amor por sí mismo (philautía). Según Gadamer, Aristóteles niega la idea de que los seres humanos son capaces de cualquier tipo de “autoposesión” que los absuelva de la necesidad de tener amigos" (George, 2010, p. 308). 
vinculación en vivencias cotidianas cada vez más abiertas al otro muy cercano y al otro distante; es to es, que "también en el otro y en lo diferente puede realizarse una especie de encuentro consigo mismo. Con todo nunca se ha hecho más necesario aprehender a reconocer en el otro y la diferencia lo común" (Gadamer, 2001b, p. 186). La amistad es una experiencia, una de las experiencias en las que debemos aprender el gesto de la hospitalidad con la finitud que somos, la amistad es apertura a uno mismo y a lo otro.

Evidentemente es amistad lo que añade Aristóteles: reconocerse en el otro y que el otro se reconozca en uno. Pero no solo en el sentido de «así es ese», sino también en el de concedernos recíprocamente el ser diferentes, más aún en palabras de Droysen: «así tienes que ser, pues así es como te quiero». Esto es la verdadera amistad, Aristóteles la llama amistad de la areté. (Gadamer, 2002b, p. 84) ${ }^{11}$

En conclusión, siguiendo a Gadamer, se nos abre el horizonte para entender que en la experiencia de la amistad aflora una posibilidad para aliviar de alguna forma el padecimiento que nos aqueja, la amistad pensada junto a los griegos nos puede conducir a explorar alternativas frente a las prácticas dominadas por la instrumentalización creciente de nuestro mundo de la vida determinado por la tecnificación. Hoy se nos hace más urgente pensar juntos lo que la tradición nos ha heredado, pues quizás en ella podamos descubrir nuevas constelaciones de sentido que nos permitan continuar el diálogo infinito que somos, comprender finalmente que en la experiencia de la amistad el sí mismo y el otro descubren que "solo un amigo puede aconsejar a otro, o dicho de otro modo, solo un consejo amistoso puede tener sentido para el aconsejado. También aquí se hace claro que el hombre comprensivo no sabe ni juzga desde una situación externa y no afectada, sino desde una pertenencia específica que le une al otro, de manera que es afectado por él y piensa con él” (Gadamer, 2001a, p. 395).

11 Siguiendo lo anterior señalemos que "los amigos no son los mismos, no buscan rehacer al otro en su propia imagen. Más bien ellos reconocen y aprecian la distinción de ese otro con uno. [...] La amistad, entonces, involucra obligaciones y un respeto por la diferencia que conduce al autoconocimiento y una adhesión al ser" (Warnke, 2012, p. 9). 
Referencias

Aristóteles. (2010). Ética a Nicómaco. (Trad. J. Pallí Bonet). Madrid: Gredos.

Caputo, J. (2002). Good Will and Hermeneutics of Friendship: Gadamer and Derrida. Philosophy \& Social Criticism, 28(5), pp. 512-522. Disponible online en: http://psc.sagepub.com/content/28/5/512.extract.

Delgado, C. (2011). La comprensión como camino del reconocimiento: tras las huellas de la diferencia. M. Prada (Comp.), Ensayos sobre hermenéutica y educación (pp. 201-218). Bogotá: Editorial Bonaventuriana.

Delgado, C. (2012). La experiencia de la lectura. Aproximación a la hermenéutica de Hans-Georg Gadamer. Bogotá: Uniediciones.

Delgado, C. (2013). Entre el extrañamiento y lo común. En torno a la noción de amistad desde la hermenéutica de Gadamer. Folios. Revista de la facultad de bumanidades, 38, pp, 3-14.

Esquirol, J.M. (2015). La resistencia intima. Ensayos de una filosofía de la proximidad. Barcelona: Acantilado.

Gadamer, H.-G. (1993). El aislamiento como síntoma de autoenajenación. Elogio de la teoría. Discursos y artículos (pp. 109-123). Barcelona: Península.

Gadamer, H-G. (1999). Friendship and Self-Knowledge: Reflections on the Role of Friendship in Greek Ethics. Hermeneutics, Religion and Ethics (pp. 128-142). Yale: Yale University.

Gadamer, H.-G. (2001a). Verdad y método I. (Trad. A. Agud \& R. de Agapito). Salamanca: Sígueme.

Gadamer, H.-G. (2002a). Verdad y método II. (Trad. M. Olasagasti). Salamanca: Sígueme.

Gadamer, H.-G. (2001b). Ciudadano de dos mundos. El giro hermenéutico. (pp. 173-186). Madrid: Cátedra.

Gadamer, H.-G. (2002b). Acotaciones hermenéuticas. (Trad. A. Agud \& R. de Agapito). Madrid: Trotta.

Gadamer, H.-G. (2010). Phronesis: Una filosofía de la finitud. El último dios. La lección del siglo XX. Un diálogo filosófico con Riccardo Dottori (pp. 23-34). Barcelona: Ánthropos. 
George, Th. (2010). De la invisibilidad a la intimidad: Honneth, Gadamer y el reconocimiento del otro. M. del R. Acosta (Ed.), Reconocimiento y diferencia. Bogotá: Siglo del hombre Editores.

Gutiérrez, C. (2010). La alteridad de Gadamer a Hegel. M. del R. Acosta (Ed.), Reconocimiento y diferencia. Bogotá: Siglo del hombre Editores.

Han, Ch.-B. (2012). La sociedad del cansancio. Barcelona: Herder.

Han, Ch.-B. (2013). La sociedad de la transparencia. Barcelona: Herder.

Risser, J. (1996). The Other Voice in Gadamer's Hermeneutics. L.E. Hahn (Ed.), Philosophy of Hans-Georg Gadamer: Library of Living Philosophers (pp. 391399). Chicago: Open Court Publishing Company.

Warnke, G. (2012). Solidarity and Tradition in Gadamer's Hermeneutics. History and Theory, Theme Issue 51. Middletown: Wesleyan University.

Walhof, D. (2006). Friendship, Otherness, and Gadamer's Politics of Solidarity. Political Theory, 34(5), pp. 570-588.

Zoja, L.(2014). La muerte del prójimo. Manuscrito inédito cedido por el autor. 